\title{
Experimental Research on the Wettability of Recycled Aggregate Concrete with Fly Ash
}

\author{
Yuanchen Guo $^{1,2,}$, Xue Wang ${ }^{2}$ and Jueshi Qian ${ }^{1}$ \\ ${ }^{1}$ College of Materials Science and Engineering,Chongqing University, No.174, Shazheng Street, Shapingba District, \\ Chongqing 400030, China \\ ${ }^{2}$ College of Civil Engineering, Chongqing Three Gorges University, 780 ShaLong Road, Wanzhou District, Chongqing \\ City 404100,China
}

\begin{abstract}
Material adsorption, the reverse process of evaporation diffusion, directly reflects the wettability of materials. Wettability is one of the main factors that affect the drying shrinkage of materials. A device that measures the wettability of recycled aggregate concrete (RAC) with fly ash is proposed in this study based on pore structure theory. The isothermal absorption curve of RAC is examined with different fly ash contents. Results show that as the recycled aggregate replacement rate increases, the moisture absorption capacity of RAC gradually increases. The addition of fly ash improves the porosity of RAC structures and reduces material wettability.
\end{abstract}

Keywords: Recycled aggregate concrete; wettability; fly ash; drying shrinkage; experimental research.

\section{INTRODUCTION}

Recycled aggregate concrete (RAC) refers to new concrete prepared with recycled concrete aggregate (RCA), which is made with construction waste to replace or partially replace the natural aggregate. Many experts have conducted numerous experimental studies on the drying shrinkage of concrete materials. The results of these studies show that under similar experimental conditions, RAC exhibits greater shrinkage deformation than natural aggregate concrete (NAC) [1-7]. However, RAC is rarely used because of the physical and mechanical defects of RCA. Thus, reducing RAC material shrinkage and improving the crack resistance of RAC materials have become important research topics.

Non-uniform concrete shrinkage often occurs during the initial use period and is caused mainly by moisture diffusion inside the material [8]. Therefore, studying initial moisture absorption is important for RAC drying shrinkage research. The isothermal moisture properties of the material are related to the composition and structure of the material itself. The wettability of cement-based materials is based on isothermal absorption curves. In China, Li [9] studied the expanded polystyrene board, extruded polystyrene board, and polyurethane insulation of three commonly used building insulation materials. Yang [10] investigated the building materials used in raw soil enclosure structures. However, only a small amount of data on RAC moisture absorption exists overseas. Furthermore, the test equipment for isotherm moisture

*Address correspondence to this author at the College of Materials Science and Engineering,Chongqing University, No.174, Shazheng Street, Shapingba District, Chongqing 400030, China; Tel: +8615025576096;

Fax: +86 23 58102281; E-mail: gyc1982@aliyun.com absorption and adsorption requires high precision. The test is difficult to implement because it requires much time. Therefore, a device that measures RAC moisture absorption is proposed in this study based on pore structure theory.

\section{EXPERIMENTAL DESIGN}

\subsection{Experimental Principle}

The Washburn dynamic method is the most common means of testing solid contact angles. It is expressed as Eq. (1).

$h^{2}=(\gamma R \cos \theta / 2 \eta) t$

where $h$ is the height in $\mathrm{cm}$ of the water rise over time $\mathrm{t} ; R$ is the effective capillary radius in $\mathrm{cm} ; \gamma$ is liquid surface tension in dyne/cm; and $\eta$ is the viscosity of the liquid in Pa.s.

The $h^{2}-t$ diagram approximates a linear line. Slope $k$ is computed with Eq. (2) and is used to obtain contact angle $\theta$ in Eq. (3).

$$
\begin{aligned}
& k=\gamma R \cos \theta / 2 \eta \\
& \theta=\arccos (2 k \eta / \gamma R)
\end{aligned}
$$

The increased height $h$ of the liquid in RAC is difficult to measure accurately. Thus, the $h^{2}-t$ curve tested in the experiment is replaced by the $m^{2}$ - $t$ curve according to the characteristics of the cement-based composite materials, where $m$ is the increased weight of the liquid in RAC. A capillary bundle parallel is formed within RAC by the large number of cylindrical pores in the capillary channel beam. 
The relationship of water quality $m$ and water rising height $h$ is shown in Eq. (4).

$m=\varepsilon \cdot h \cdot \rho_{w} \sum s_{i}$

where $m$ is the weight in $g$ of the water sunk into RAC over time $t ; \varepsilon$ is the porosity of RAC to the decimal meter; $h$ is water rising height in $\mathrm{cm}$ over time $t ; \rho_{w}$ is the water density; and $s_{i}$ is the $i$ th sectional area of the cylindrical capillary tube.

Therefore,

$m^{2}=\left(\varepsilon \cdot \rho_{W} \cdot \sum s_{i}\right)^{2} \cdot((\gamma R \cos \theta / 2 \eta) t$

$k=\left(\varepsilon \cdot \rho_{W} \cdot \sum s_{i}\right)^{2} \cdot(\gamma R \cos \theta / 2 \eta)$

As shown in Eq. (5), the $m^{2}$-t curve should approximate a straight line.

Given the difficulty in determining the effective radius $R$ of the capillary bundle, effective radius $R$ is replaced in this study with effective radius $R_{m}$ of the capillary bundle model (assuming uniform distribution and that all pores are cylindrical and continuous). Its value can be approximately expressed as Eq. (7).

$R_{m}=\left(2 \varepsilon \cdot V_{S J} /(l \cdot \pi)\right)^{1 / 2}$

where $\varepsilon$ is the porosity of RAC; $V_{S J}$ is the volume of the samples; and $l$ is the specimen height.

Thus, Eq. (4) and (5) are transformed into Eq.(8) and (9).

$m^{2}=\left(\varepsilon \cdot \rho_{W} \cdot \sum s_{i}\right)^{2} \cdot\left(\left(\gamma R_{m} \cos \theta / 2 \eta\right) t\right.$

$k=\left(\varepsilon \cdot \rho_{W} \cdot \sum s_{i}\right)^{2} \cdot\left(\gamma R_{m} \cos \theta / 2 \eta\right)$

As a result, the contact angle is

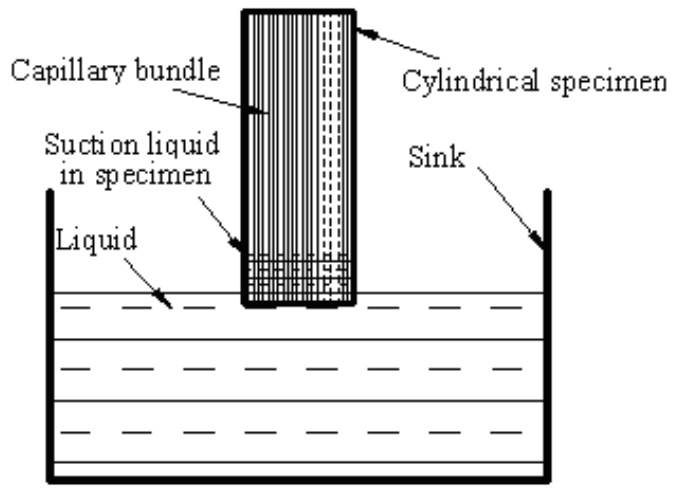

Fig. (1). Simplified diagram of the wettability testing device.

$\theta=\arccos \left(2 k \eta / \gamma R_{m}\right)$

\subsection{Experimental Materials, Equipment, and Methods}

Construction waste (CW) was obtained from a building demolition in Chongqing City, China. The cement was $\mathrm{P} \cdot \mathrm{S}$ 32.5. The physical properties of the fly ash are shown in Table 1.

Fig. (1) shows the design principles of the device used to measure the contact angle of RAC. The cylindrical RAC specimen was placed inside a mold with an inner diameter of $4.5 \mathrm{~mm}$ and an outer diameter of $5 \mathrm{~mm}$.

The mix design of RAC, which employs C30 natural mix proportion as a reference, is shown in Table 2. Each sample was loaded into the device (shown in Fig. (1)) three times, and each appropriate plug was pounded. The sample and the mold were then placed in a standard curing room for conservation. After $7 \mathrm{~d}$, a drying test was performed at $80^{\circ} \mathrm{C}$ [11] until the sample weight became constant. Afterward, under the conditions of $60 \%$ humidity and $20^{\circ} \mathrm{C} \pm 2{ }^{\circ} \mathrm{C}$, the rate of water loss from the sample was tested to calculate the

Table 1. Physical Properties of the Fly Ash Used in the Experiment

\begin{tabular}{|c|c|c|c|c|}
\hline Product Grade & Fineness (\%) & Water Demand Ratio (\%) & SO $_{\mathbf{3}}$ (\%) & Loss on Ignition (\%) \\
\hline \hline I & 7.3 & 112 & 1.87 & 0.63 \\
\hline
\end{tabular}

Table 2. Mix Design of RAC $\left(\mathrm{kg} / \mathrm{m}^{3}\right)$

\begin{tabular}{|c|c|c|c|c|c|c|c|c|c|}
\hline Project & Number & Cement & NA & RCA & Sand & Water & Sand ratio & W/C & FA \\
\hline \multirow{2}{*}{ RCA replacement ratio } & RC70 & 426 & 300 & 700 & 560 & 200 & 0.36 & 0.47 & 0 \\
\hline & RC100 & 426 & 0 & 1000 & 560 & 200 & 0.36 & 0.47 & 0 \\
\hline \multirow{3}{*}{ Fly ash Content } & FA10 & 426 & 0 & 1000 & 560 & 200 & 0.36 & 0.47 & 43 \\
\hline & FA20 & 426 & 0 & 1000 & 560 & 200 & 0.36 & 0.47 & 85 \\
\hline & FA30 & 426 & 0 & 1000 & 560 & 200 & 0.36 & 0.47 & 128 \\
\hline
\end{tabular}


contact angle of RAC.

\section{EXPERIMENTAL RESULTS AND ANALYSIS}

The effects of the recycled aggregate and fly ash on RAC hygroscopic capacity $\mathrm{m}^{2}$ is shown in Figs. (2a) and (3a), respectively.

As shown in Fig. (2a), the moisture absorption capacity of RAC increases with the increase in the recycled aggregate replacement rate mainly because of the existence of numerous cracks and the porosity and age of the cement mortar in the recycled aggregate itself. Cracks, porosity, and cement mortar age cause high water absorption in the recycled aggregate, thereby increasing the moisture absorption capacity of RAC. Porosity and old cement content in RAC increase as the RCA replacement rate increases.

As shown in Fig. (3a), the moisture absorption capacity of RAC decreases with the increase in fly ash content; however, the decline is not obvious possibly because the porosity of RAC with fly ash gradually declines when the amount of fly ash is increased.

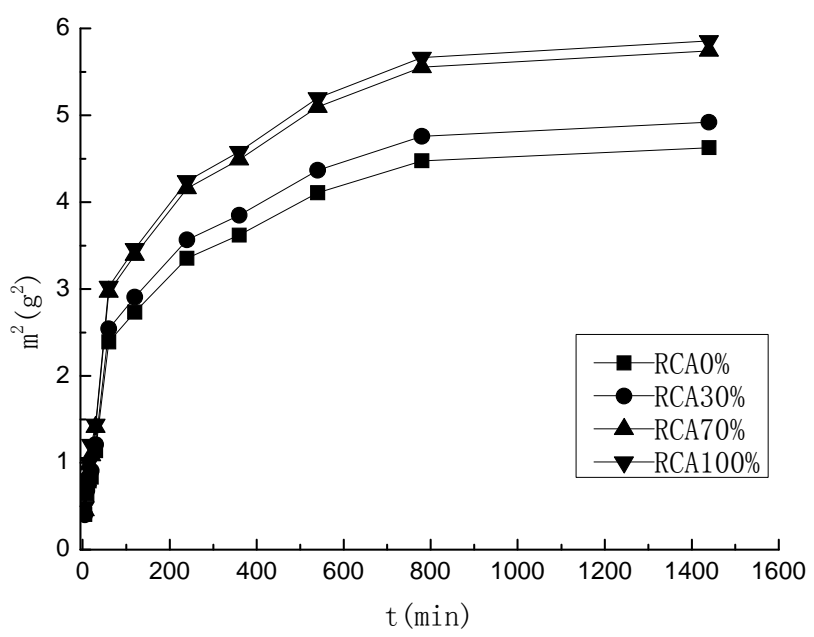

(a)
Figs. (2b) and (3b) show the linear fitting curve obtained with the $\mathrm{m}^{2}$-t curve in the first $20 \mathrm{~min}$. Slope $k$ is obtained from this linear fitting curve. $\cos \theta$ and contact angle $\theta$ are calculated according to Eqs. (9) and (10). The calculated results are shown in Table 3 .

The contact angle decreases with the increase in the recycled aggregate replacement rate as shown in Table 3. This result indicates that the wetting properties are upgraded gradually. The value of $\cos \theta$ increases with the increase in the recycled aggregate replacement rate from the point of view of material wettability alone. Eq. (11) indicates that with the increase in $\cos \theta$, compressive stress $P$ of the entire wall of pores also increases; the shrinkage of RAC increases as well.

$$
P=P_{c} \cdot \cos \theta=\frac{2 \sigma}{r} \cdot \cos \theta
$$

where $P$ is the compressive stress of entire wall; $\sigma$ is surface water tension; $r$ is the radius of the curved surface; and $\theta$ is the contact angle.

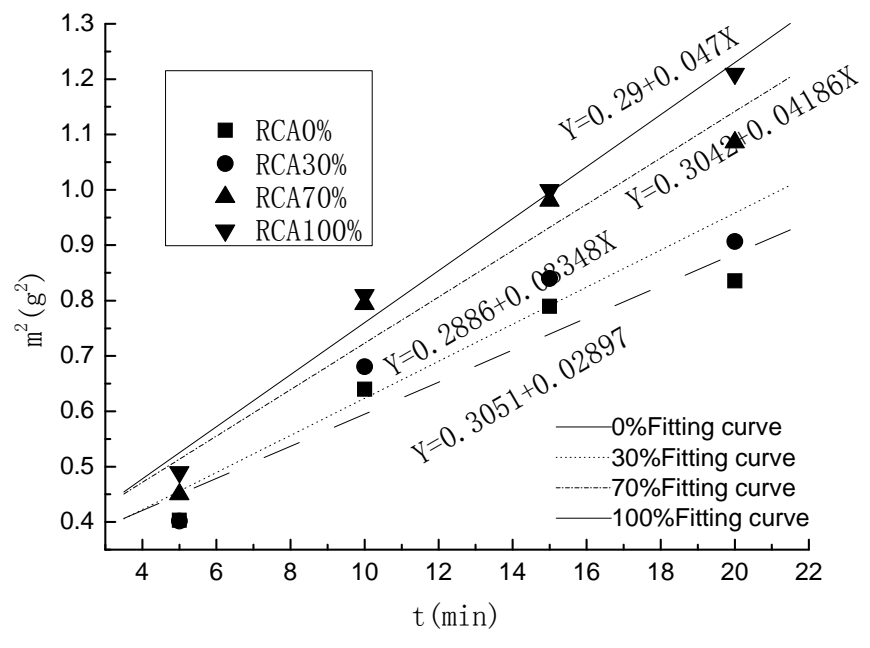

(b)

Fig. (2. a,b). Effect of the recycled aggregate on hygroscopic capacity $m^{2}$.

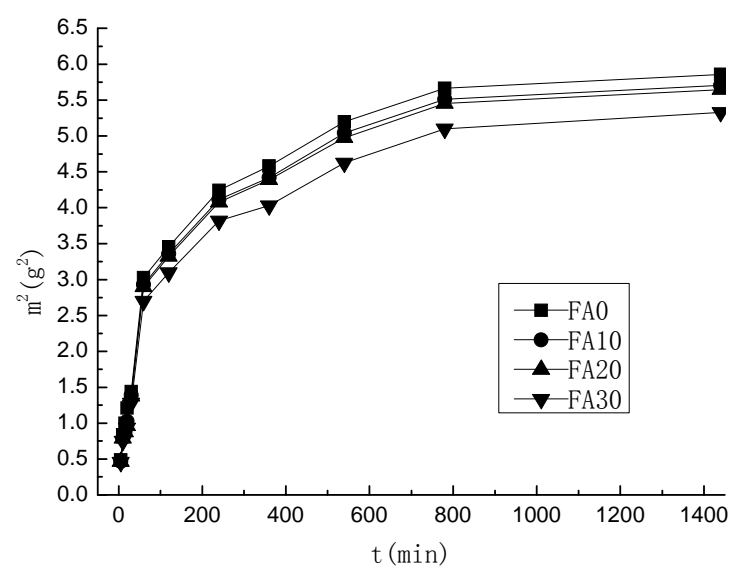

(a)

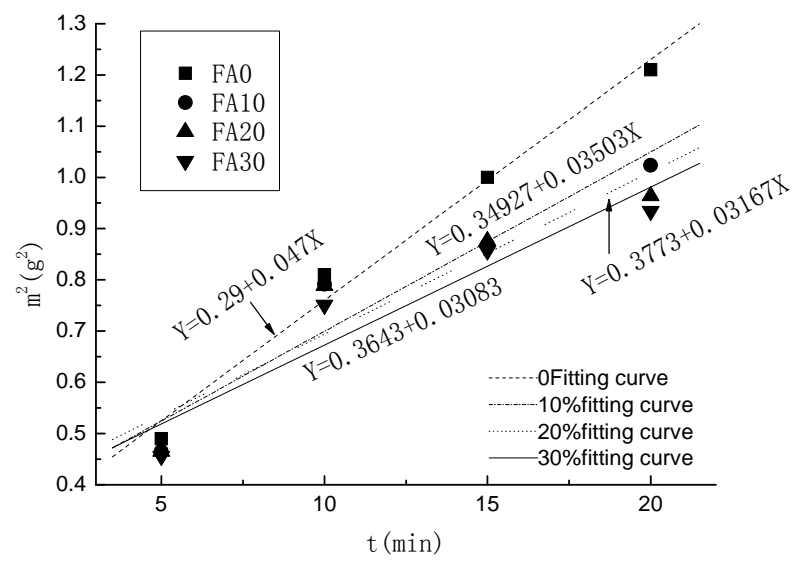

(b)

Fig. (3. a,b). Effect of fly ash content on hygroscopic capacity $m^{2}$. 
Table 3. Contact Angle

\begin{tabular}{|c|c|c|c|}
\hline Experiment Number & $\mathbf{k}$ & $\cos \theta$ & $\theta\left({ }^{\circ}\right)$ \\
\hline \hline RC0 & 0.02897 & 0.2589 & 75.0 \\
\hline RC30 & 0.03348 & 0.2847 & 73.5 \\
\hline RC70 & 0.04186 & 0.3082 & 68.7 \\
\hline RC100 & 0.0470 & 0.3641 & 68.7 \\
\hline FA0 & 0.0470 & 0.3641 & 71.7 \\
\hline FA10 & 0.03503 & 0.3131 & 72.0 \\
\hline FA20 & 0.03167 & 0.3085 & 73.5 \\
\hline FA30 & 0.03083 & 0.2831 & \\
\hline
\end{tabular}

The contact angle increases with the increase in fly ash mixing amount. In other words, wettability gradually decreases; however, the decrease is not obvious mainly because capillary porosity is reduced when fly ash is added. When fly ash particles participate in hydration, the system hydration rate increases. Thus, the self-drying speed of the inner concrete increases with the increase in fly ash mixing amount.

Fig. (4) shows an SEM image of the hydration products of RAC with fly ash. The solid volume increases during the hydration of fly ash. Fly ash is squeezed around the cement hydration products, resulting in an original loose worm-like calcium-silicate-hydrate (C-S-H) creep. The C-S-H creep increases the density of the hardened cement paste structure, reduces the number of pores, and could cut off and refine these pores. In addition, the cement hydration product $\mathrm{Ca}(\mathrm{OH})_{2}$ is consumed during fly ash hydration. Fly ash hydration greatly reduces the $\mathrm{Ca}(\mathrm{OH})_{2}$ crystal content in the aggregate interface and cement paste and improves the uniformity and density inside the concrete (as shown in Fig. 4). The $\cos \theta$ value decreases with the increase in fly ash content. The compressive stress $P$ of the entire wall of pores also decreases according to Eq. (8). Thus, the shrinkage value of RAC is small at the same intensity of capillary wall.

\section{CONCLUSION}

(1) The addition of fly ash improves the porosity of RAC structures and reduces the wettability of the material, thereby possibly reducing the water diffusion rate of RAC. Thus, the addition of fly ash inhibits the shrinkage deformation of RAC.

(2) The solid volume increases during fly ash hydration. Fly ash is squeezed around the cement hydration products, resulting in an original loose worm-like $\mathrm{C}-\mathrm{S}-\mathrm{H}$ creep.

(3) The $\cos \theta$ value decreases with increased fly ash content from the point of view of $\theta$ alone.

(4) The contact angle decreases with the increase in the recycled aggregate replacement rate, which may in turn increase the water diffusion rate and result in greater RAC shrinkage.

\section{CONFLICT OF INTEREST}

The authors confirm that this article content has no conflicts of interest.
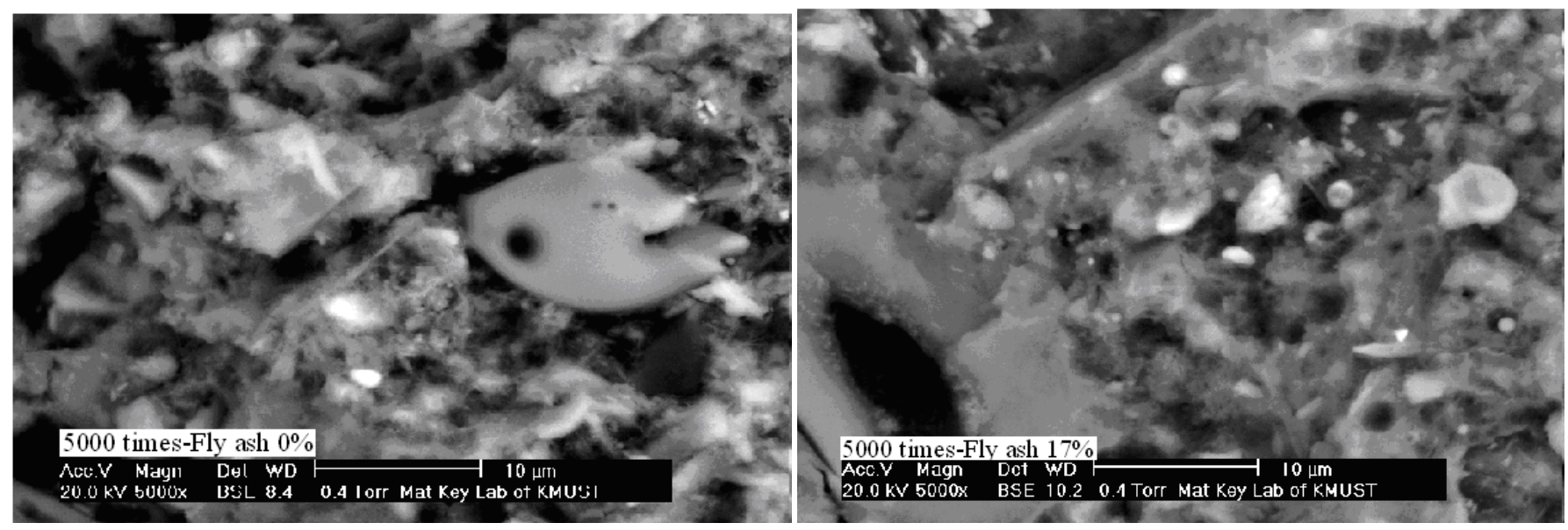

Fig. (4). SEM image of the hydration products of RAC with fly ash. 


\section{ACKNOWLEDGEMENT}

This project was supported by the Project of National Natual Science Foundation of China (51202304), Natural Science Foundation Project of CQ CSTC (cstc2012jjA50005).

\section{REFERENCES}

[1] S. Hasaba, and M. Kawamure "Drying shrinkage and durability of the concrete made of recycled concrete aggregate", Transaction of the Japan Concrete Institute, no. 3, pp. 55, March 1981.

[2] W. X. Wang, L. Liu, L. Z. Shang, and L. Wang, "Research on recycled concrete aggregate”, Chinese Concrete and Cement Products, no. 4, pp. 9-12, March 2001.

[3] A. Katz, "Properties of concrete made with recycled aggregate from partially hydrated old concrete", Cement and Concrete Research, vol. 33, no. 5, pp. 703-711, May 2003.

[4] F. Debieb and S. Kenai, "The use of coarse and fine crushed bricks as aggregate in concrete”, Construction and Building Materials, vol. 22, no. 5, pp. 886-893, May 2008.
[5] L. Courard, F. Michel, and P. Delhez, "Use of concrete road recycled aggregates for roller compacted concrete", Construction and Building Materials, vol. 24, no. 3, pp. 1-6, March 2008.

[6] A. Domingo-Cabo, C. Lázaro and F. López-Gayarre, "Creep and shrink age of recycled aggregate concrete”, Construction and Building Materials, no. 3, pp. 545-2553, May 2009.

[7] L. Evangelista, and J. Brito, "Durability performance of concrete made with fine recycled concrete aggregates", Cement and Concrete Composites, vol. 32, no. 1, pp. 9-14, January 2009.

[8] H. D. Huang, Z. F. Xiang and J. L. Zheng, "Analysis of differential shrinkage deflection for PC box-girder bridges”, Architectural \& Environmental Engineering, vol. 3, no. 1, pp. 60-65, January 2009.

[9] K. S. Li, X. Zhang, X. Han, and D. M. Zhu, "Experimental research of isothermal sorption curve of building materials", Journal of Building Materials, vol. 12, no. 1, pp. 81-84, January 2009.

[10] Z. F. Yan, J. P. Liu, and R. S. Wang, "Experimental study of moisture absorption isotherms of adobe building materials", Journal of Xian University of Architecture \& Technology, vol. 35, no. 4, pp. 327-353, April 2003.

[11] M. Sand, S. A. Abo-El-Eneim, G. B. Hanna and M. F. Kotkata, "Effect of temperature on physical and mechanical properties of concrete containing silica fume”, Cement and Concrete Research, vol. 26, no. 5, pp. 37-41, May 1996.

(C) Gou et al.; Licensee Bentham Open.

This is an open access article licensed under the terms of the Creative Commons Attribution Non-Commercial License (http://creativecommons.org/licenses/ by-nc/3.0/) which permits unrestricted, non-commercial use, distribution and reproduction in any medium, provided the work is properly cited. 